\title{
ANTONIO CANDIDO, CRIADOR DA ÁREA DE TEORIA LITERÁRIA E LITERATURA COMPARADA
}

http://dx.doi.org/10.11606/issn.2237-1184.v0i30p11-24

\section{Sandra Nitrini ${ }^{I}$}

\section{RESUMO}

\begin{abstract}
Amparado na sua atuação de crítico literário, ainda como professor de Sociologia, Antonio Candido percebeu que havia uma carência de estudos gerais introdutórios e estudos teóricos especializados, indispensáveis para uma boa formação acadêmica dos estudantes de Letras, ao contrário do que ocorria em outras faculdades e em outros cursos, nas quais já existiam disciplinas com este objetivo. Ele se valerá desta observação para fundamentar sua sugestão de se criar uma disciplina deste teor no curso de Letras, encaminhada à Congregação da, então, Faculdade de Filosofia, Ciências e Letras da USP e aprovada em 1959.

A atuação de Antonio Candido como professor que inaugurou o campo de estudos teóricos e comparativos na USP constitui o foco principal deste artigo, que contempla também um memento dos colaboradores que contribuíram e dos que contribuem atualmente para o desenvolvimento da Área de Teoria Literária e Literatura Comparada.
\end{abstract}

\section{ABSTRACT}

Supported by his performance as a literary critic, and as Sociology professor at USP, Antonio Candido realized that there was a lack of general introductory studies and of specialized theoretical studies, fundamental for a good academic education for Literature students, in opposition to what happened in other colleges and courses, that already had disciplines for this purpose. He will use this observation to substantiate his suggestion to create a discipline of this content in the Literature course, sent to the Congregation of the Faculdade de Filosofia, Ciências e Letras of the University of São Paulo, at the time, which was approved in 1959.

Antonio Candido's role as the professor who inaugurated the field of theoretical and comparative studies at USP is the main focus of this article, which also includes a memento of the collaborators who have contributed and those who currently contribute to the development of the Literary Theory and Comparative Literature area.

\section{PALAVRAS-CHAVE:}

Antonio Candido;

Teoria Geral da Literatura;

Teoria Literária e Literatura

Comparada;

Letras;

corpo docente.

\section{KEYWORDS}

Antonio Candido;

General Literature Theory;

Literary Theory and Comparative

Literature;

Language and Literature;

teaching staff.

\footnotetext{
' Universidade de São Paulo, São Paulo, São Paulo, Brasil.
} 
m 1959, Antonio Candido, então assistente de Sociologia, sugeriu a criação da Cadeira de Teoria Geral da Literatura. Sua proposta encontrou ressonância no corpo docente e foi encaminhada à Congregação da Faculdade de Filosofia, Ciências e Letras da USP, tendo sido aprovada por unanimidade na reunião do dia 10 de setembro. Nesse mesmo ano lançou Formação da literatura brasileira: momentos decisivos. De modo que 1959 foi um ano especial para o curso de Letras da USP, intimamente ligado ao nome de Antonio Candido com a aprovação da disciplina de Teoria Geral da Literatura e com a publicação de seu livro, fundamental como poucos serão em nossa cultura", no dizer de Antonio Callado e na experiência e convicção de seus milhares e milhares de leitores, ao longo desses quase sessenta anos.

Amparado na sua atuação de crítico literário, Antonio Candido percebeu que havia uma carência de estudos gerais introdutórios e estudos teóricos especializados, indispensáveis para uma boa formação acadêmica dos estudantes de Letras, ao contrário do que ocorria em outras faculdades e em outros cursos, nas quais já existiam disciplinas com este objetivo, como Introdução ao Estudo do Direito, Teoria Geral do Estado, Teoria Geral da Educação, Introdução aos Estudos Históricos e Introdução à Filosofia. Ele se valerá desta observação para fundamentar a sugestão de se criar uma disciplina deste teor no curso de Letras.

Este argumento de grande força para dar igualdade de condições curriculares ao curso de Letras em relação aos demais se reveste de especificações qualitativas ao considerar que "uma cadeira desta amplitude tem importância primordial na formação literária do estudante, por importar numa confrontação de pontos de vista, antigos e modernos, convergência e síntese dos estudos especiais e irradiação do pensamento crítico e renovador, através da análise das tendências atuais da literatura", palavras que constam do documento da Congregação destinado ao Conselho Universitário, ao submeter para sua avaliação a proposta de criação da Cadeira de Teoria Geral e certamente da autoria de Antonio Candido ou inspiradas por suas manifestações ao tratar deste assunto com seus pares.

A área de Teoria Literária e Literatura Comparada começou a integrar o curso de Letras em 1961, como Cadeira de Teoria Geral da Literatura. No ano seguinte, passou a se chamar Teoria Literária e Literatura Comparada por iniciativa de Antonio Candido, para se assegurar o estudo das literaturas estrangeiras e um espaço institucional para a Literatura Comparada. Iniciativa que não poderia deixar de ser tomada pelo autor da Formação da literatura brasileira, livro que constitui o 
testemunho cabal de que a história da literatura brasileira, em seu período de formação, acha-se vinculada a modelos estrangeiros e não escapa a uma aproximação comparatista.

De 1961, quando se inaugura a Cátedra, até 1964, Antonio Candido, único professor, encarregou-se dos cursos destinados aos alunos do primeiro e do quarto anos da Graduação, cada um com duas aulas semanais, para os períodos diurno e noturno, lembrando que naquela época as disciplinas eram anuais e vigia o sistema de cátedras. Na programação divulgada para o ano de 1961 (prática que se instalou na Faculdade de Filosofia, Letras e Ciências Humanas, a partir de 1960, por decisão de uma Congregação de 1959), o curso do primeiro ano intitula-se Introdução ao Estudo da Literatura e o do quarto ano, Análise crítica do romance (dividido em duas partes: Teoria e Técnica).

$O$ professor Antonio Candido ministrava ainda o curso de especialização, também nos dois períodos. Este curso consistia num seminário duplo por semana. Na ementa apresentada na programação divulgada para 1961, o curso de especialização, O exercício crítico da ficção, assim é descrito "Análise adiantada de obras de ficção, com vistas a um ensaio pessoal redigido pelo aluno, sobre obras escolhidas em combinação com o professor, que tomará duas para objeto de explicação e ponto de reparo".

Em 1964, o curso de Teoria Literária e Literatura Comparada passou a ter um número de alunos bem maior que o do ano inaugural da cadeira, o que propiciou ao professor Antonio Candido contar com o apoio de um instrutor, encarregado de coordenar os seminários, "para análise de textos ilustrativos dos diversos aspectos estudados nas aulas", de acordo com a descrição do programa divulgado. A cada grupo de seis aulas ministradas pelo professor, seguiam-se dois seminários sob a responsabilidade do instrutor, Roberto Schwarz, que tinha voltado ao Brasil, em 1963, depois de uma estadia de dois anos nos Estados Unidos, onde apresentou seu mestrado na Universidade de Yale, sob a orientação de René Wellek.

Houve alteração do número de carga horária do curso do primeiro ano, Introdução à Teoria Literária, de duas para uma aula. Note-se a mudança do nome da disciplina, de Introdução ao Estudo da Literatura, de 1961, para Introdução à Teoria Literária, dando ênfase à dimensão teórica, mais coerente com a motivação da criação desta cadeira, fundamentada na necessidade de um espaço "em que se estudam e se exponham, de forma sistemática, as teorias da literatura, da estética, crítica e história literárias, para uma constante revisão de ideias e valores, e reconstrução, à luz das pesquisas mais recentes, de uma " teoria geral da literatura", reproduzindo-se aqui trecho do documento da Congregação, citado anteriormente.

Cabe ressaltar que duas linhas mestras foram adotadas no curso de Teoria da Literatura e Literatura Comparada desde o começo: "ensinar de 
maneira aderente ao texto, evitando teorizar demais e procurando mostrar de que maneira os conceitos lucram em ser apresentados como instrumentos de prática imediata, isto é, de análise", nas palavras de Antonio Candido. ${ }^{2}$ É de se ressaltar ainda a opção do professor Antonio Candido de trabalhar com textos de autores clássicos para cursos dos primeiros anos, enquanto os alunos do quarto ano e da Especialização tinham a oportunidade de estudar escritores do Modernismo e de entrar em contato com os clássicos de maneira atualizada. O que para os inícios dos anos de 1960 representava uma inovação, quase que uma ousadia, pois naquela época ainda os estudos literários estavam fadados a se circunscreverem a autores do passado mais longínquo. A ênfase ao estudo concreto da obra literária e à abertura à literatura moderna decorre da vivência acadêmica, literária, cultural e intelectual do criador do campo de estudos da teoria literária e literatura comparada, lembrando sua atuação como crítico literário e sua participação no grupo da revista Clima.

Voltemos para o curso de Teoria Literária e Literatura Comparada de 1964. Mantiveram-se as duas aulas para o quarto ano. Também se manteve o curso de especialização com uma inovação: o curso passou a se desenvolver em duas partes, cada qual com duas horas semanais: uma dedicada à Linguagem e Estilo em Cinema, a cargo do Prof. Paulo Emílio Sales Gomes; outra dedicada ao Seminário de Análise Poética, sob a responsabilidade de Antonio Candido. Também cabe aqui pontuar a preocupação de Antonio Candido em trazer para os estudantes de Letras o acesso a outra linguagem artística, imprescindível para o estudioso da literatura e antecipando para seus estudantes o que hoje chamamos o estudo da relação entre artes, ainda que o curso se estruturasse em partes separadas: uma dedicada ao cinema, outra à literatura.

Além de todas essas atividades didáticas, Antonio Candido instituiu para o doutoramento o Seminário do Círculo de Literatura Comparada, sobre formulação de problemas e métodos de investigação, também com duração de duas horas semanais, sob sua responsabilidade. De modo que ele oferecia aos estudantes de especialização e de doutoramento, dois vieses da Literatura Comparada: entre literaturas e entre literatura e outra arte.

Dentre os primeiros cursos, assinalam-se, para o quarto ano, o de Teoria e Análise do romance (1961-1962) e o de O estudo analítico do poema (1963-1964). Parte deste curso foi mimeografado por seus alunos, à revelia de Antonio Candido. Mais de 20 anos depois, o professor permitiu sua publicação pela FFLCH, motivado por uma perspectiva histórica à medida em que "este material já pode ser considerado como elemento para a sua história, como amostra do que se fazia naquele tempo, antes das

2 “O estudo analítico do poema”. São Paulo: FFLCH-USP, s.d., p. 6. 
transformações e, em consequência, o seu ensino", no entanto, ele se revela ainda atual e integra a bibliografia de Introdução aos Estudos Literários, disciplina obrigatória do ano básico de Letras, constituindo um de seus itens mais lidos e aproveitados pelos alunos até hoje. É um livro procurado não só pelos estudantes da USP, mas por muitos outros leitores, haja vista suas constantes reedições.

Os primeiros cursos de quinto ano ou especialização baseavam-se em seminários e aulas centradas num problema, visando à aquisição de técnicas avançadas de trabalho. Assim, foram ministrados nesse nível o curso de Ecdótica (Edição Crítica), com investigação e análise de manuscritos e o de crítica textual, tendo como objeto de aplicação contos de Machado de Assis, em 1961; seminários sobre Quincas Borba, a cargo do professor e dos alunos, com o objetivo de construir uma interpretação coletiva, em 1962; seminários de análise de cinco poemas escolhidos a partir da obra de Manuel Bandeira, Mário de Andrade, Murilo Mendes, Carlos Drummond de Andrade e João Cabral de Mello Neto, em 1963.

Referindo-se a essa época, Antonio Candido lembra que, durante meses, em 1962, ele e seus alunos analisaram o poema Louvação da Tarde de Mário de Andrade. No decorrer dos seminários surgiu a ideia do levantamento de suas anotações marginais, o que foi efetuado por Maria Helena Grembecki, Nites Teresinha Ferer e Telê Porto Ancona Lopez. Segundo o próprio Antonio Candido, este levantamento talvez tenha sido o primeiro impulso no processo de incorporação do acervo deste escritor ao Instituto de Estudos Brasileiros. Valendo-se do material colhido, as três pesquisadoras realizaram suas dissertações de mestrado e teses de doutoramento sobre aspectos da obra de Mário de Andrade, dando início a um ciclo de pesquisas, documentação e estudos sobre a obra deste grande escritor e sobre o Modernismo em geral.

Mais docentes vêm compor a Área de Teoria Literária e Literatura Comparada ainda na década de 1960: Walnice Nogueira Galvão (1965), João Alexandre Barbosa (1967) e Davi Arrigucci Jr. (1967). Em 1968, Roberto Schwarz já não mais fazia parte do quadro atuante de docentes, pois mudara-se para Paris, por injunções da ditadura daquela época. ${ }^{3} \mathrm{Um}$ ano depois, uma nova docente no curso: Teresa de Jesus Pires Vara.

Com a reforma da FFLCH em 1969, extinguiu-se o regime de cátedras e foram criados dois Departamentos de Letras: o de Clássicas e Vernáculas e o de Modernas. Ficaram fora deles duas disciplinas gerais, a de Teoria Literária e Literatura Comparada e a de Linguística. Essa mesma reforma deslocou do Departamento de História os recém-criados Estudos Orientais. Por conveniência dessas disciplinas, sem grandes afinidades, mas que necessitavam juridicamente da massa crítica que, àquela época, só

\footnotetext{
3 Doutorou-se em Estudos Latino-Americanos pela Universidade de Paris III (Université Sorbonne Nouvelle III) sob orientação de Raymond Cantel em 1976.
} 
Teoria Literária e Literatura Comparada podia fornecer para a constituição de um Departamento e com a generosa anuência acadêmica dos professores Antonio Candido e Isaac Nicolau Salum, da área de Linguística, surgiu um Departamento anômalo, como sempre foi o de Linguística e Línguas Orientais, em cujo nome jamais figurou Teoria Literária e Literatura Comparada, disciplina sem a qual ele não teria existido.

De 1969 até 1990, ano da criação do Departamento de Teoria Literária e Literatura Comparada, manteve-se na graduação o esquema curricular inicial, com pequenas modificações, constituindo sempre um primeiro ano de Introdução aos Estudos Literários e um quarto ano de Teoria Literária e Literatura Comparada, os quais se tornaram semestrais em 1969. Quase vinte anos depois, em 1988, a disciplina de Teoria Literária e Literatura Comparada se desdobrou para se garantir um espaço no currículo de Letras, no qual os alunos tivessem acesso, de um lado, à discussão e sistematização das questões do núcleo central da Teoria Literária, voltado par o problema do modo de ser da obra literária, de sua compreensão crítica e para uma série de assuntos afins, e de outro, à análise e reflexão de problemas específicos da Teoria da Literatura Comparada, campo de estudos literários que passou a ser alvo de um interesse renovado no Brasil, nos anos de 1980. Introdução aos Estudos Literários, então disciplina optativa, exceto para o curso de Linguística, passa a integrar o currículo mínimo de Letras em 1990. Posteriormente, na primeira década do século XXI, outras disciplinas optativas foram implantadas: Correntes Críticas e Literatura e Educação.

Quanto ao quinto ano ou especialização, até 1971 o curso foi centralizado em Antonio Candido, professor responsável por duas das três disciplinas obrigatórias que compunham seu currículo: Teoria Literária e Literatura Comparada A e Teoria Literária e Literatura Comparada B. A outra, Teoria e História do Cinema ficava a cargo de Paulo Emílio Salles Gomes. O aluno deveria ainda seguir uma disciplina optativa, escolhida entre Sociologia da Arte, ministrada por Ruy Coelho e Estética, por Gilda de Mello e Souza. As quatro disciplinas eram anuais. O curso não conferia título de mestrado ou doutorado. Este poderia ser obtido depois, por meio de dissertação ou tese, se o aluno o desejasse e fosse aceito pelo orientador. No entanto, ele tinha direito a um certificado de pós-graduação. Esta estrutura tinha forte unidade, derivada do fato de que os dois cursos de Teoria eram dados pelo mesmo professor. Por outro lado, a componente interdisciplinar também era contemplada. Com a passagem para o regime novo da pós-graduação em 1971, a interdisciplinaridade continuou a ser possível, embora não mais obrigatória e nem articulada ao eixo de Teoria Literária. Este eixo deixou de ser único. As disciplinas tornaram-se semestrais e passaram a ser ministradas por vários orientadores. Ressalvese, contudo, que a perda destes louváveis traços do currículo da primeira 
fase da pós-graduação em Teoria Literária e Literatura Comparada foi compensada pela própria riqueza da diversidade de pontos de vista, introduzidos pelos professores que começaram a atuar na área no início da década de 70.

Voltando aos primeiros docentes da Área, todos, exceto Roberto Schwarz, todos doutoram-se sob orientação de Antonio Candido, o que assegurou, a despeito de diferenças de origem, de formação acadêmica e de preferências por diferentes teorias e correntes críticas, uma afinidade no sentido de não se cultivar a teorização, desvinculada da leitura concreta da obra literária e da relação desta com a sociedade.

A eles viriam juntar-se na década de 1970: Lígia Chiappini Moraes Leite e Lucila Ribeiro Bernardet (1973) e João Luiz Machado Lafetá (1978). Exceto Lucila, orientada por Paulo Emílio Salles Gomes, ambos fizeram mestrado e doutorado sob a orientação de Antonio Candido.

Essa leva de docentes da década de 1970 faz parte, num certo sentido, da primeira geração que atuou na Área de Teoria Literária e Literatura Comparada, no período em que Antonio Candido estava presente no cotidiano acadêmico da FFCLH, até se aposentar em 1978, embora tenha continuado na pós-graduação até 1992. Atuou ainda na graduação e na pós-graduação, na condição de professora colaboradora, contratada, Marlyse Meyer, entre fins dos anos 70 e inícios de 80. Os professores Boris Schnaiderman e Aurora Fornoni Bernardini, de Literatura Russa, passaram a integrar o corpo docente da pós-graduação, ministrando cursos e orientando pós-graduandos, no decorrer dos anos, mesmo depois de suas aposentadorias, contribuindo para a implementação e solidificação do programa da pós-graduação da área. Colaborou ainda no início desta etapa de pós-graduação a profa. Onédia Barbosa, da área de inglês. ${ }^{4}$

Na década de 1980, houve uma ampliação do quadro docente, com o ingresso de Iumna Maria Simon (1981, doutorado com João Alexandre Barbosa), Sandra Margarida Nitrini (1982, mestrado com Greimas, na Escola Prática de Altos Estudos de Paris e doutorado com Davi Arrugucci Jr.), Regina Lúcia Pontieri (1987, mestrado e doutorado com Teresa de Jesus Pires Vara), Cleusa Rios Pinheiro Passos (1988, mestrado com Jean Fabre, Universidade Paul Valéry, em Montpellier,e doutorado com Davi Arrigucci Jr). Tendo sido essas quatro docentes orientandas de exorientandos de Antonio Candido, podemos dizer que elas constituem a segunda geração de professores da Área.

\footnotetext{
${ }^{4}$ No decorrer dos anos, docentes de outras áreas da FFLCH foram credenciados para ministrar cursos e orientar dissertações e teses, como Willi Bölle, de literatura alemã; Philippe Willemart, de literatura francesa; Sandra Guardini Vasconcelos, de literatura inglesa. O mais recente professor credenciado, Adriano Schwartz, pertence ao quadro docente da EACH. Outros professores, colaboradores ou contratados temporariamente, contribuíram com a Área, como Modesto Carone e Berta Waldman, da Unicamp.
} 
Os docentes de Teoria Literária e Literatura Comparada vinham discutindo há muito tempo a idéia de constituição de um Departamento, com o intuito de obter melhores condições para desenvolver seu projeto acadêmico que incluía, entre outras atividades, a expansão de cursos optativos para o aluno de Letras e da Faculdade. A rigor, esta discussão vinha desde o início da década de 1980.

A criação do Departamento foi aprovada pela Congregação em 10 de dezembro de 1987, mas só se consolidou em 21 de junho de 1990, com o reconhecimento oficial da Universidade. Nesta ocasião, o responsável pela Área era Davi Arrigucci Jr., veio a se tornar o primeiro chefe do Departamento.

Na data da instalação oficial do Departamento, havia 16 docentes, dentre os quais oito tinham ingressado por processo de seleção em 1989: Adélia Bezerra de Menezes, que tinha sido orientanda de Antonio Candido, no mestrado e doutoramento, e já era docente doutora há muitos anos na Unicamp; Ariovaldo José Vidal, na época mestrando em Literatura Brasileira, sob a orientação de Alcides Villaça; posteriormente se doutoraria, em Teoria Literária, sob a orientação de Davi Arrigucci Jr.; Claudia de Arruda Campos, mestre em Literatura Brasileira, sob a orientação de Décio de Almeida Prado; faria depois seu doutoramento em Teoria Literária, sob a orientação de Lígia Chiappini Moraes Leite; Iná Camargo Costa, mestre em Estética, sob a orientação de Otília Arantes, com quem continuaria seu doutoramento; Ivone Daré Rabello, mestranda em Teoria Literária, sob a orientação de João Luiz Lafetá,e doutorado sob a orientação de Iná Camargo Costa; Joaquim Alves de Aguiar, mestrando em Teoria na Unicamp, sob a orientação de Maria Lúcia Dal Farra, faria posteriormente seu doutoramento sob a orientação de Davi Arrigucci Jr.; Rita de Cássia Natal Chaves, doutoranda em Literatura Africana, sob a orientação de Benjamin Abdalla Jr., tendo já defendido mestrado sob sua orientação, e Roberto Ventura, doutor em Teoria Literária e Literatura Comparada, que tinha sido orientado por João Alexandre, e que já trazia o título de doutor da Alemanha. Fizera seu mestrado na PUC do Rio, com Silviano Santiago.

Essa terceira geração de docentes, com formação diversificada, integrou-se na vida acadêmica do DTLLC, dando, com atualizações teóricas, continuidade à tradição da perspectiva dos estudos de teoria literária e literatura comparada.

Intensificou-se a diversificação de origem dos novos docentes, a partir dos anos 90, fato decorrente da expansão da universidade e dos cursos de pós-graduação e do acesso à universidade por concursos públicos: Marcus Vinicius Mazzari (1996, mestrado em Literatura Alemã, sob a orientação de Willi Bölle, com doutorado na Universidade Livre de Berlim, sob a orientação de Scherpe), Maria Augusta Fonseca(1997,com mestrado e doutorado em Teoria Literária e Literatura Comparada, sob a 
orientação de Boris Schnaiderman), Viviana Bosi (1998, mestrado na Faculdade de Educação da USP, sob a orientação de Maria Teresa Fraga Rocco, e doutorado em Teoria Literária e Literatura Comparada, sob a orientação de Davi Arrigucci Jr.), Andréa Saad Hossne (1998, mestrado e doutoramento em Teoria Literária e Literatura Comparada, sob orientação de Sandra Margarida Nitrini).

A partir de 2000, seja para substituir docentes aposentados e Roberto Ventura, infelizmente falecido precocemente, seja para atender parte das reivindicações da greve dos alunos da FFLCH, de 2002, movimento iniciado pelos alunos de Letras, diante da precária situação das salas de aula, foram admitidos novos docentes propiciando, assim, uma renovação do quadro permanente de professores. Constituem a última leva de docentes do DTLLC: Fábio de Souza Andrade (2000, mestrado e doutorado em Teoria Literária e Literatura Comparada, sob a orientação de Davi Arrigucci Jr.), Jorge de Almeida (2001, doutorado em Estética, sob a orientação de Paulo Arantes), Roberto Zular (2002, doutorado em Literatura Francesa, sob a orientação de Philippe Willemart), Marco Natali (2003, mestrado e doutorado em Literatura Comparada, na Universidade de Chicago, sob a orientação de Dipesh Chacabrart) e Betina Bischof (também em 2003, doutoramento em Teoria Literária e Literatura Comparada, sob a orientação de Davi Arrigucci Jr.), Eduardo Vieira Martins (2004, mestrado e doutorado na Unicamp, sob a orientação de Luiz Carlos da Silva Dantas), Samuel Titan e Ana Paula Sá e Souza Pacheco (2005, ambos com doutorado em Teoria Literária e Literatura Comparada, sob a orientação de Davi Arrigucci Jr.), Marta Kawano (em 2007, com mestrado em filosofia, com Luiz Henrique Lopes dos Santos e doutorado em Teoria Literária e Lite-ratura Comparada, sob a orientação de Sandra Nitrini e co-orientação de Davi Arrigucci Jr.), Edu Teruki também em 2007 (com mestrado e doutorado em Literatura Brasileira, sob a orientação, respectivamente, de Claudia Arruda Campos e de José Antonio Pasta Jr.) e, por último, Anderson Gonçalves da Silva (2013, doutorado em Filosofia, sob a orienta-ção de Paulo Eduardo Arantes).

Compartilhar linhas mestras e objetivos gerais é absolutamente necessário para que uma equipe tenha sua identidade. Por isso, os professores do DTLLC discutem com frequência seu projeto acadêmico, não apenas por injunções institucionais, por ocasião das avaliações, mas por uma necessidade interna de compreensão da própria identidade. Modificações e adaptações de linhas de pesquisa foram feitas em função do perfil do quadro docente do momento, mas se manteve o eixo medular da Teoria Literária e Literatura Comparada da USP, cujas coordenadas foram lançadas, quando da criação deste campo de estudos.

Não se trata de uma postura conservadora e acrítica nem de uma inércia intelectual, mas da opção dos docentes ao longo dos anos por continuarem a priorizar a obra literária, razão de ser da própria teoria e crítica 
literárias, sem desconsiderar sua relação com outros saberes e com outras artes, como bem mostram as linhas de pesquisa desenvolvidas nos últimos anos e como foram cultivadas desde as primeiras disciplinas da Área de Teoria Literária e Literatura Comparada.

Em recente relatório de avaliação, o DTLLC reafirma que "almeja, dando continuidade à sua tradição pioneira na área, contribuir decisivamente para a formação de profissionais atentos às questões teóricas e críticas dos estudos literários, e participar ativamente dos debates nacionais e internacionais sobre Teoria Literária e Literatura Comparada", com a perspectiva de constante atualização. Tais palavras ecoam propósitos que motivaram a criação deste campo de estudos, palavras coincidentes com muitas que compuseram o documento argumentativo em prol da criação da antiga Cadeira de Teoria Geral da Literatura.

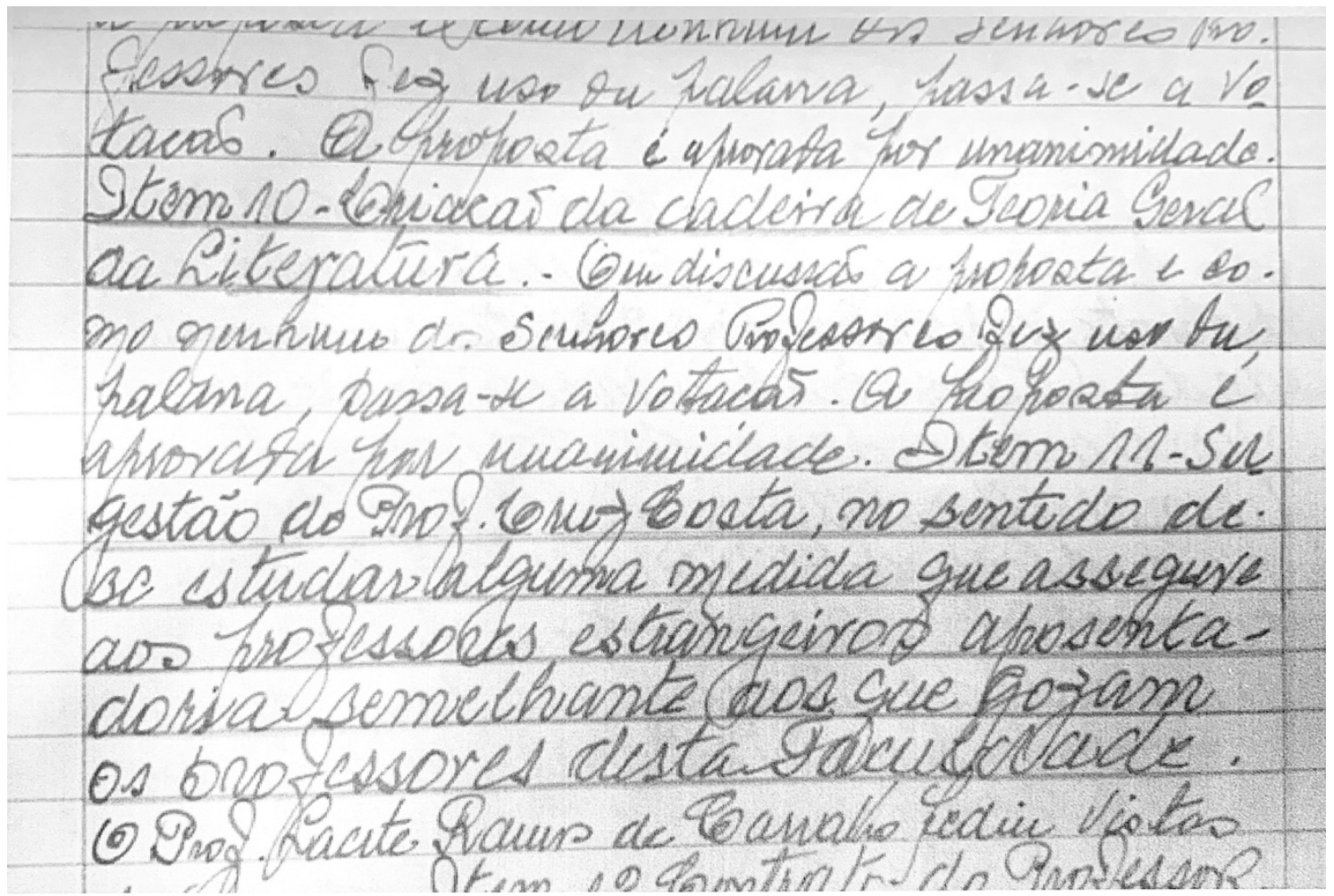

Trecho manuscrito da ata que se refere à criação da Cadeira de Teoria Literária (1959). 
Ementas dos programas da cadeira de Teoria Literária dos anos de 1961 e 1964, publicadas pela FFCL:

CURSO DE TEORIA GERAL DA LITERATURA

Professor: Dr. Antônio Cândido de Mello e Souza (contratado:

Introdução ao Estudo da Literatura.

1. ${ }^{\circ}$ Ano

(2 aulas semanais, cursos diurno e noturno).

1. Matéria e forma da criação literária.

2. A classificação das obras.

3. Os recursos expressivos.

4. Análise de textos.

5. Noções de investigação literária.

$$
\text { 4. Ano }
$$

\section{Análise Crítica do Romance.}

( 2 aulas semanais, cursos diurno e noturno).

I - Teoria.

1. O problema da crítica de romance.

2. Esquema geral de análise.

3. O enrêdo e o foco narrativo.

4. Os personagens.

5. O ambiente novelístico.

6. O tempo narrativo.

7. A estrutura.

8. O estilo.

9. A coerência.

10. A verossimilhança.

11. O significado humano e artístico.

II - Técnica.

Estudo de um romance brasileiro a ser indicado.

\section{ESPECIALIZAÇÃO}

\section{O exercício da crítica de ficçăo.}

(1 seminário duplo por semana, para diurno e noturno).

Análise adiantada de obras de ficção, com vistas a um ensaio pessoal redigido pelo aluno, sôbre obras escolhidas em combinação com o professor, que tomará duas para objeto de explicação e ponto de reparo. 


\section{TEORIA LITERARIA E LITERATURA COMPARADA}

(Curso)

Professor: Antônio Cândido de Mello e Souza

Instrutor: Lic. Robert Schwarz

Programas para 1964

$$
\begin{gathered}
\text { 1. Ano } \\
\text { Diurno e Noturno } \\
1 \text { aula semanal }
\end{gathered}
$$

\section{INTRODUÇÃO À TEORIA LITERÁRIA}

1. Natureza da literatura.

a. universalidade b. modalidades c. função.

2. Os fatôres externos da obra.

a. sociais b. culturais c. psíquicos.

3. Os fatôres internos.

a. normas b. gêneros c. estilo.

4. O destino da obra.

a. fortuna no tempo e no espaço b. influência entre as obras c. influência na vida.

5. Modos de estudar a obra.

a. erudito b. histórico c. analítico d: ensaístico.

NOTA: Os alunos deverão realizar trabalhos mensais para aquisição da técnica de análise literárià nos diversos niveis estudados no programa. Esta parte ficará a cargo do Instrutor, Lic. Roberto Schwarz.

$$
\begin{gathered}
\text { 4. } .^{\circ} \text { Ano } \\
\text { Diurno e Noturno } \\
2 \text { aulas semanais } \\
\text { O ESTUDO ANALITICO DO POEMA }
\end{gathered}
$$

1. Os fundamentos do poema.

a. sonoridade b. ritmo c. mietro d. verso.

2. As unidades expressivas.

a. imagem b. tema c. alegoria d. símbolo.

3. A estrutura.

a. princípios estruturais b. princípios organizadores c. sistemas de integração.

4. Os significados.

a. sentido ostensivo e latência b. tradução intelectual c. poesia "direta" e "oblíqua". d. clareza e obscuridade.

5. A unidade do poema. 
NOTA: No curso, cada grupo de seis aulas será seguido de dois seminários a cargo do Instrutor ,para análise de textos ilustrativos dos diversos aspectos estudados nas aulas.

\section{Especialização}

O curso terá duas partes, ministradas paralelamente durante o ano todo:

\section{Parte I:}

\section{Linguagem e Estilo em Cinema}

(A cargo do Prof.: Paulo Emílio Salles Gomes) (2 horas semanais)

A - O problema da simultaneidade narrativa no nascimento da linguagem cinematográfica.

1. Registro e descrição no cinema primitivo (de Lumière à Escola de Brighton).

2. Ilustração e narração (Zecca e Porter).

3. A linguagem e o estilo de David Wark Griffith.

B - Simultaneidade e montagem.

4. Ambição de autonomia estética.

5. Alcance e limite do vanguardismo.

6. A linguagem e estilo de Serguei Mikhailovitch Eisenstein.

NOTA: As ilustrações do curso constarão de filmes projetados em horário variáveḷ, em cooperação com a Fundação Cinemateca Brasileira.

\section{Parte II:}

\section{Seminário de Análise Poética}

(A cargo do Prof.: Antônio Cândido de Mello e Souza)

( 2horas semanais)

Textos do Prof. Carlos Drumiond de Andrade, Murilo Mendes e João Cabral de Melo Neto.

\section{Doutoramento}

Seminário do Círculo de Literatura Comparada, sôbre formulação de problemas e métodos de investigação.

NOTA: Salvo menção expressa em contrário, os cursos serão dados pelo Prof. de Teoria Literária e Literatura Comparada.

Fontes: Documentos que constam do Processo de Criação do Departamento, em sua maioria, encaminhados e assinados por Walnice Nogueira Galvão, então responsável pela Área de Teoria Literária e Literatura Comparada; Relatórios de Avaliação do Departamento, Ata da Congregação da Faculdade Filosofia, Ciências e Letras de 10 de setembro de 1959, Processo de Criação da Cadeira de Teoria Geral da Literatura e documentos de programação das disciplinas. 
Sandra Nitrini é professora titular sênior do Departamento de Teoria Literária e Literatura Comparada da Faculdade de Filosofia, Letras e Ciências Humanas da Universidade de São Paulo. É autora de Literatura Comparada: história, teoria e crítica (2010, $3^{\mathrm{a}}$ ed.); Um olhar sobre a Literatura Comparada no Brasil (Cadernos do IEB, n. 10, 2018, publicação online); Transfigurações: ensaios sobre a obra de Osman Lins (2010) e Poéticas em confronto: Nove, novena e o Novo Romance (1987). Organizou individualmente ou em parceria vários livros, dentre os quais o último, Memória $\mathcal{E}$ Trauma Histórico: Literatura e Cinema (2019), co-organizado por Andrea Saad Hossne, é o resultado de um projeto de pesquisa internacional, "Memória e Literatura", parceria da USP com as Universidades Francesas Lyon2, Lyon3, École Normale Supérieure de Lyon e com a Universidade S. Martin, de Buenos Aires, no âmbito de um projeto mais amplo e pluridisiciplinar. Desenvolve pesquisas sobre teorias da Literatura Comparada e a história da Literatura Comparada, sobre a literatura de viagem de autoria de escritores e intelectuais brasileiros com destino à França na primeira metade do século XX e sobre o lugar de Osman Lins na Literatura Brasileira, a partir de sua correspondência com colegas, de suas aulas de Literatura Brasileira e de seus artigos e de suas manifestações sobre escritores brasileiros. É pesquisadora do CNPq $1 \mathrm{~A}$ e membro do Grupo de Pesquisa Brasil-França do IEA (USP). Contato: snitrini@usp.br

ORCiD: https:// orcid.org/0000-0001-8117-0586 